\title{
A case report of von Willebrand disease complicated with gastric antral angiodysplasia
}

\author{
BV Hasheni' ${ }^{1}$ PDN Perera ${ }^{2}$, MK Ragunathan ${ }^{3}$ \\ ${ }^{1}$ Registrar in Medicine, ${ }^{2}$ Resident Physician, ${ }^{3}$ Consultant Physician, Karapitiya Teaching Hospital, \\ Galle.
}

\section{Introduction}

von Willebrand disease (vWD) is the most common inherited bleeding disorder in human and it is characterised by qualitative and quantitative defect in vW factor (vWF) [1,2]. The disease has three main types and many subtypes and most of them have autosomal dominant inheritance. Association of vascular abnormalities in the gut is a rare occurrence.

\section{Case report}

A 56 year old male, diagnosed to have diabetes and vWD, presented with a short history of malena and symptoms of severe anaemia. He has no history of bleeding from any other sites. He has been suffering from vWD in a sub clinical state for 30 years and his diabetic control was satisfactory with diet control. He has been on iron therapy for 5 years for previously diagnosed iron deficiency anaemia. He was not on long term treatment with other drugs. There was a death of a family member possibly due to a bleeding disorder.

On examination he was pale but haemodynamically stable. Examination of other systems was unremarkable. There was no external evidence of muscle haematoma.

Initial ancillary blood investigations revealed sudden drop of haemoglobin level from $12 \mathrm{~g} / \mathrm{dL}$ to $6 \mathrm{~g} / \mathrm{dL}$. White cell and platelet counts were normal. Blood picture showed many polychromatic cells, normocytic normochromic red cells and occasional spherocytes. Reticulocytes $8 \%$. Coomb's test negative. APPT 90 sec control 32 sec, PT 12 sec control $11 \mathrm{sec}$, AST 19 U/L, ALT 10 U/L, ALP 4 KAU. RBS 198 mg/dL, BU 30 $\mathrm{mg} / \mathrm{dL}$. US scan abdomen was normal.
He was transfused with blood and cryoprecipitate as an immediate measure. Upper Gastro Intestinal Endoscopy (UGIE) was arranged and it revealed massive amount of altered blood covering the gastric mucosa. He was started on intravenous tranexamic acid $500 \mathrm{mg}$ bd, intranasal desmopressin and intravenous pantoprazole $40 \mathrm{mg}$ daily. APPT and haemoglobin levels were reassessed. Second OGD uncovered severe erosive gastritis with edematous mucosa.

He was asymptomatic and discharged but readmitted with similar symptoms.

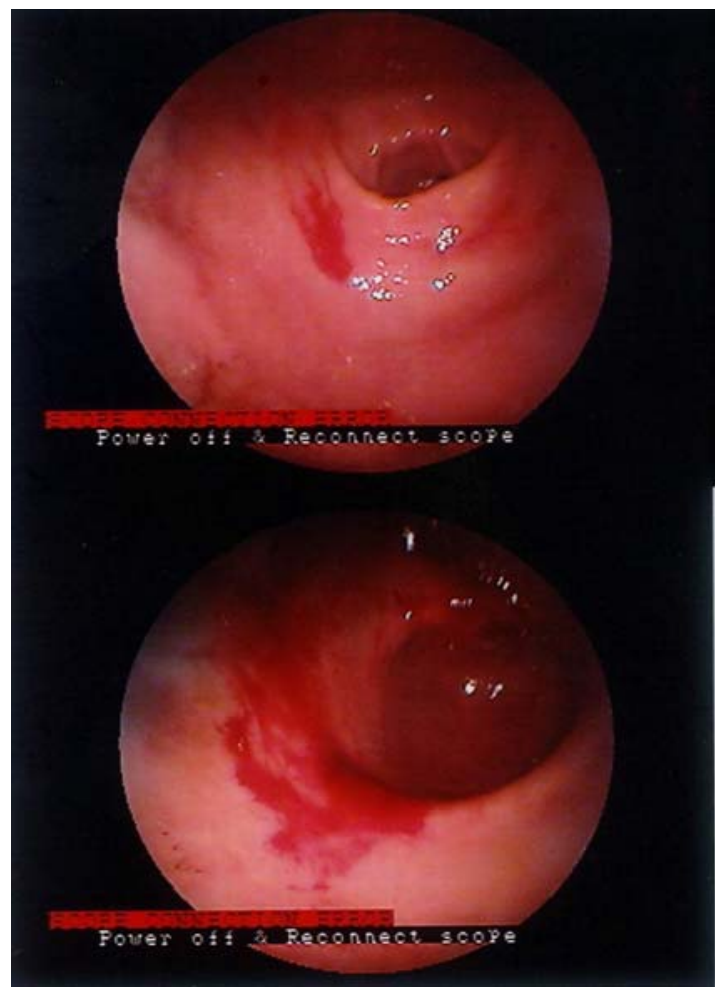

Figure 1

This time, UGIE clearly demonstrated a bleeding arterio-venous malformation at the gastric antrum (Fig 1) for which adrenalin 1/10000 was injected locally. Later, endoscopic tissue glue application 
was tried but it was unsuccessful. Subsequently he underwent gastric antrectomy and gastroduodenostomy under cover of intermediate purified factor VIII and recovered completely. But later colonoscopy revealed multiple angiodysplasias in the gut.

\section{Discussion}

Recurrent upper GI bleeding with sudden drop of haemoglobin in a patient with vWD is suggestive of associated GIT angiodysplasia. The terms 'angiodysplasias', 'arteriovenous malformations', and 'vascular ectasias' have been used synonymously [2]. Literature survey revealed an association between vWD and angiodysplasia of GIT, but whether this association is a part of Hereditary Haemorrhagic Telangectasia (HHT) is questionable [3-7].

Angiodysplasia may be single or multiple. Therefore patients should be screened for other lesions in the gut if recurrent bleeding occurs. Recombinant activated factor VII (rFVIIa) should be considered as a supportive therapy [5].

Different local treatment modalities such as endoscopic therapies like electrocoagulation, band ligation, sclerotherapy, and laser, are available but the success rates are variable [2]. The definitive treatment is surgical resection [2]. Hormonal therapy (estrogen +/- progesterone) has been used to control obscure gastrointestinal bleeding in few patients [2,7].

\section{References}

1. Lefrancois C, Dubus L, Maurel J, Chiche L, Lavergne JM, Borel-Derlon. Digestive haemorrhage disclosing an angiodysplasia and von Willebrand's disease type II Annals French Anaesthesia Reaim 1997; 16(8): 97881. French. PMID 9750649.

2. Peter A L Bonis, MD T Edward Bynum. Medicine “Angiodysplasia of the GI Tract, Uptodate 2005.

3. Rosborough TK, Swaim WR. Acquired von Willebrand's disease, platelet release defect and angiodysplasia. American Journal of Medicine 1978; 65(1): 96-100. PMID 308316

4. Ramsay DM, Buist TA, Macleod DA, Heading RC persistent gastrointestinal bleeding due to angiodysplasia of the gut in vWD. The Lancet 1976; 2(7980): 275-8.

5. Meijer K, Peters FT, van der Meer J. Recurrent severe bleeding from gastrointestinal angiodysplasia in a patient with von Willebrand's disease, controlled with recombinant factor VIIa Blood Coagul Fibrinolysis 2001; 12(3): 211-3. PMID11414636.

6. Cass AJ, Bliss BP, Bolton RP, Cooper BT. Gastrointestinal bleeding, angiodysplasia of the colon and acquired von Willebrand's disease. British Journal of Surgery 1980; 67(9): 639-41. PMID69686.

7. Angiodysplasia and von Willebrand's disease type IIB treated with estrogen / progesterone therapy. American Journal of Hematology 1992; 41(4): 276-85. 